\title{
Angiotensin-converting enzyme inhibitors, angiotensin-II-receptor antagonists and angiotensin-receptor blocker/neprilysin inhibitor utilization in heart failure patients: Sub-analysis of a nation-wide population-based study in the Czech Republic
}

\author{
Renata Aiglova a, Milos Taborsky ${ }^{\mathrm{a}}$, Marie Lazarova ${ }^{\mathrm{a}}$, Ludek Pavlua , Josef Danek ${ }^{\mathrm{b}}$, Jan Preceka, Alexander Schee ${ }^{\mathrm{c}}$, Vit Gloger ${ }^{\mathrm{d}}$, \\ Vlastimil Cernicek ${ }^{\mathrm{d}}$, Marek Vicha ${ }^{\mathrm{a}}$, Tomas Skala ${ }^{\mathrm{a}}$
}

\begin{abstract}
Aims. Sub-analysis of a retrospective nation-wide observational analysis of heart failure (HF) epidemiology reported to the Czech National Registry of Reimbursed Health Services between 2012 and 2018 aimed at angiotensin-converting enzyme inhibitors (ACEI), angiotensin-II-receptor antagonists (ARB) and angiotensin receptor blocker/neprilysin inhibitor (ARNI) use.

Methods and Results. ACEi and ARBs were generally used in 87.6\% of all HF patients in 2012 ( $\mathrm{n}=154627) ; 84.5 \%$ in 2013 ( $n=170$ 861); 83.5\% in 2014 ( $n=186$ 963); 81.6\% in 2015 ( $n=198$ 844); 80.1\% in 2016 ( $n=205$ 793); $78.0 \%$ in 2017 $(n=212152)$ and in 76.7\% in 2018 ( $n=219235)$. In a sub-analysis of patients with a medical procedure and/or examination using an I50.x ICD code accounted for in the given year, ACEi and ARBs were generally used in $99.3 \%$ in 2012 ( $n=63$ 250); 96\% in 2013 ( $n=62$ 241); 95.2\% in 2014 ( $n=64$ 414); 93.3\% in 2015 ( $n=65$ 217); 91.8\% in 2016 ( $n=65$ 236); 90.1\% in 2017 ( $n=65761)$ and in 88.6\% in 2018 ( $n=66$ 332). In 2018, the majority of patients with HF were prescribed ramipril $(n=49909 ; 17.5 \%)$ and perindopril $(n=44332 ; 15.5 \%)$. The mostly prescribed ARBs in 2018 were telmisartan $(n=18669$; 6.5\%); losartan ( $n=13935 ; 4.9 \%)$ and valsartan ( $n=4849 ; 1.7 \%)$. In 24.5\% of cases, ACEls and ARBs were prescribed in a fixed combination with another drug. ARNI became gradually more prescribed from 2018 ( $n=9659$ in November 2020). Conclusion. In an analysis of ACEIs, ARBs and ARNIs utilization in all patients treated for heart failure in the given year in the whole country, we found a comparable rate of drug prescription in comparison with specific heart failure registries. This indicates a good translation of current standard of care into common clinical practice. Ramipril and perindopril remained the mostly prescribed ACEls and telmisartan became the mostly prescribed ARB. Since 2018, ARNIs began to be widely prescribed.
\end{abstract}

Key words: angiotensin-converting enzyme (ACE) inhibitors, angiotensin-Il-receptor antagonists, sacubitril/ valsartan, heart failure, European Union, Czech Republic

Received: January 3, 2021; Revised: May 21, 2021; Accepted: May 28, 2021; Available online: June 4, 2021 https://doi.org/10.5507/bp.2021.035

(c) 2022 The Authors; https://creativecommons.org/licenses/by/4.0/

${ }^{a}$ Department of Internal Medicine I - Cardiology, University Hospital Olomouc, Olomouc, Czech Republic ${ }^{b}$ Department of Internal Medicine, Military University Hospital Prague, Prague, Czech Republic 'Cardio center, Regional Hospital Karlovy Vary, Karlovy Vary, Czech Republic

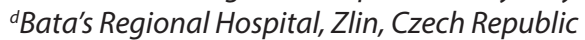

Corresponding author: Tomas Skala, e-mail: tomasskala@gmail.com

\section{INTRODUCTION}

In patients with heart failure (HF), the treatment goals are improving their clinical status, functional capacity and quality of life, prevent hospital admissions and reduce mortality. The number of patients with chronic HF and especially with reduced ejection fraction of the left ventricle (HFrEF phenotype) is continually increasing. Neuro-hormonal antagonists such as angiotensin-converting enzyme inhibitors (ACEI) and angiotensin-II-receptor antagonists (ARB) improve survival in HF patients with reduced ejection fraction (HFrEF) (ref. $\left.{ }^{1}\right)$. A new compound named LCZ696 that combines angiotensin receptor blocker valsartan and neprilysin inhibitor sacubitril (ARNI) is superior to enalapril in reducing the risk of death and of hospitalization for $\mathrm{HF}^{2}$. If this evidence translates into ACEI/ARB/ARNI utilization in common clinical practice is not known. Considering use of ACEI/ ARB in HF patients, we have data from several HF registries in the Czech Republic but no registry evaluated all HF patients in the whole country ${ }^{3,4}$. It is unknown if observations from within-registry analyses can be extrapolated to non-enrolled patients. We can anticipate more frequent use of novel up-to-date evidence-based diagnostic and treatment strategies in hospitals involved in HF registries $^{5}$. This can be potentially associated with a better outcome of enrolled patients. Differences in the case-mix of the registries, age and gender distributions, and comorbidities of the participants, can influence interpretation of the results. To obtain nationwide data on HF we analyzed 
Table 1. Baseline epidemiological characteristics of HF patients.

\begin{tabular}{lccccccc}
\hline Prevalence & 2012 & 2013 & 2014 & 2015 & 2016 & 2017 & 2018 \\
\hline All & 176496 & 202135 & 223808 & 243683 & 256929 & 271907 & 285745 \\
$\geq 65$ years & 141441 & 162813 & 180990 & 198075 & 209339 & 222482 & 234120 \\
Male gender & 88591 & 101576 & 112330 & 122566 & 129867 & 137642 & 145297 \\
\hline
\end{tabular}

data from the Czech National Registry of Reimbursed Health Services which contains a complete dataset of medical claims to all health insurance companies operating within the country. Of note, few countries have reported nationwide trends in the epidemiology of HF and almost no data are available from the former Eastern bloc countries $^{6}$. Therefore, the results of this survey should be important for the planning of health expenditures, clinical research and selection of countries for clinical trials.

\section{STUDY AIM}

The aim of this study was to analyze individual types of ACEI/ARB and ARNI in all HF patients in the whole country in recent years and to compare these data with the currently available guidelines for the treatment of HF patients $^{1,7}$.

\section{METHODS}

\section{Study design}

This is a pharmacological sub-study of a retrospective observational analysis of diagnoses, procedures and treatment reported to the Czech National Registry of Reimbursed Health Services (NRRHS) between 2010 and 2018. The main time period used in the study was 2012-2018; time period 2010-2011 was included as a medical history of patients only.

\section{Patients' selection definition, data extraction and study timeline}

The patients' cohort was selected based on the International Classification of Diseases (ICD-10) data. All patients with I50.x diagnosis code accounted for in any given year (2010-2018) were selected and considered as patients with HF. Only the first HF diagnosis per single patient was taken into account. The data obtained from NRRHS include both in-patient and out-patient departments. All data were obtained in accordance with the national law and policy as anonymized results of pre-specified analyses. Data were anonymized before the linked database was released to the research group. Since this was a retrospective, anonymized study and the data are collected according to law no. 372/2011 about healthcare services, no informed consent was required.

The medical history of all HF patients was assessed, and all comorbidities recorded during 2010-2018 period. The pharmacotherapy was evaluated separately for individual types of $A C E I / A R B$ and $A R N I$.
Data about ARNi utilization until the end of 2018 are also obtained from NRRHS. However, since this is a newly emerged treatment option, ARNi prescriptions rate changed dramatically in the last two years. To reflect this, we have obtained data about ARNi prescriptions in 2019 and 2020 in the Czech Rep. directly from Novartis, Czech Republic.

\section{RESULTS}

Prevalence of HF patients, their age and gender are depicted in Table 1.

There were 176496 patients with HF in 2012 (out of 10.51 million citizens of the Czech Republic in 2012). Number of these patients grew constantly. In 2018 (10.65 million citizens of the Czech Republic in 2018), there were 285745 patients with HF (mean age $74.4 \pm 12.8$ ); slightly more men (145 297; mean age $71.5 \pm 12.5)$ than women (140 448; mean age $77.4 \pm 12.3$ ). The majority of HF patients were older than 70 years $(70.4 \%)$.

Comorbidities in HF patients in 2018 are summarized in Table 2. Cardiovascular and oncological diseases were common in HF patients. In 2018, the most prevalent were arterial hypertension (92.6\% of all HF patients) and coronary artery disease (77.9\% of all HF patients). Moreover, $62.8 \%$ of HF patients in 2018 had a history of arrhythmias, $49.7 \%$ of them had a history of AF. Diabetes mellitus (41\%) and hyperlipoproteinemia (49.6\%) were also highly prevalent. Oncological disease was present in medical history of $23.6 \%$ of patients (we report up to 40 years of history of malignancies in this cohort). The most prevalent was a non-melanoma malignant neoplasm of skin $(8.1 \%)$. Less prevalent were neoplasms of colon, rectosigmoid junction and rectum $(2.8 \%)$, breast $(2.7 \%)$ and prostate $(2.6 \%)$.

ACEi and ARBs were generally used in $87.6 \%$ of all HF patients in $2012(\mathrm{n}=154627) ; 84.5 \%$ in $2013(\mathrm{n}=170$ $861) ; 83.5 \%$ in $2014(n=186963) ; 81.6 \%$ in $2015(n=198$ $844) ; 80.1 \%$ in $2016(n=205793) ; 78.0 \%$ in $2017(n=212$ $152)$ and in $76.7 \%$ in $2018(n=219235)$. Individual types of ACEi and ARBs are depicted in Table 3.

In 2018, the majority of patients with HF were prescribed ramipril $(n=49909 ; 17.5 \%)$ and perindopril $(n=44$ $332 ; 15.5 \%)$. Their prescription rate remained similar in recent years: ramipril ( $n=41128 ; 23.3 \%$ in 2012); perindopril ( $n=33654 ; 19.1 \%$ in 2012 ). Trandolapril was prescribed in 5141 (2.9\%) of HF patients in 2012 and in 4758 (1.7\%) of HF patients in 2018. Enalapril, lisinopril, quinapril, cilazapril, fosinopril and imidapril were each prescribed in $<1 \%$ of patients in 2018. 
Table 2. Comorbidities in HF patients in 2018.

\begin{tabular}{lrc}
\hline & $\mathrm{n}$ & $\begin{array}{c}\text { \% of all HF } \\
\text { patients }\end{array}$ \\
\hline Arterial hypertension & 264499 & 92.6 \\
Coronary artery disease & 222585 & 77.9 \\
Acute myocardial infarction & 44100 & 15.4 \\
Valve disease & 85611 & 30.0 \\
Cardiomyopathy & 28487 & 10.0 \\
Arrhythmias & 179576 & 62.8 \\
Atrial fibrillation & 141988 & 49.7 \\
Stroke & 50266 & 17.6 \\
Cancer & 67393 & 23.6 \\
Diabetes mellitus & 117265 & 41.0 \\
Dyslipoproteinemias & 141764 & 49.6 \\
Chronic obstructive pulmonary & 91052 & 31.9 \\
disease & & \\
Sleep apnea & 7664 & 2.7 \\
Renal failure & 73998 & 25.9 \\
Dementia & 34534 & 12.1 \\
Alzheimer's disease & 17010 & 6.0 \\
\hline
\end{tabular}

The mostly prescribed angiotensin-II-receptor antagonist (ARB) in 2012 was losartan ( $n=17$ 390; 9.9\%) with telmisartan being the second ( $\mathrm{n}=7648 ; 4.3 \%)$ and valsartan the third ( $\mathrm{n}=4212 ; 2.4 \%)$. In 2018 this changed and telmisartan became the mostly prescribed ARB ( $\mathrm{n}=18$ 669; $6.5 \%)$; losartan the second one ( $\mathrm{n}=13$ 935; 4.9\%) and valsartan the third ( $\mathrm{n}=4849 ; 1.7 \%)$. In 2018, in $24.5 \%$ of cases, ACEIs and ARBs were prescribed in a fixed combination with another drug.

If a medical procedure and/or examination at an inpatient or out-patient department using an I50.x ICD diagnosis code was accounted for in the given year (and not just anytime during 2010-2018), ACEi and ARBs were generally used in $99.3 \%$ in 2012 ( $\mathrm{n}=63250)$; $96 \%$ in 2013 $(\mathrm{n}=62241) ; 95.2 \%$ in $2014(\mathrm{n}=64414) ; 93.3 \%$ in 2015 $(\mathrm{n}=65$ 217); $91.8 \%$ in $2016(\mathrm{n}=65236) ; 90.1 \%$ in 2017 $(\mathrm{n}=65761)$ and in $88.6 \%$ in $2018(\mathrm{n}=66332)$.

ARNI started to be reported to be prescribed in HF patients in the Czech Republic in 2017. In 2017, 0.2\% $(n=561)$ of all patients with HF were treated with ARNI; this number rose to $1.0(\mathrm{n}=2$ 862) (data from NRRHS). ARNI became gradually more prescribed since 2019 (Fig. 1). ARNis were prescribed in 4030 patients in January 2019; 7110 patients in December 2019; 9659 patients in November 2020 (data from Novartis, Czech Republic).

\section{DISCUSSION}

We retrospectively evaluated the utilization of ACEIs, ARBs and ARNIs in all HF patients in the Czech Republic $(n=10.6$ million in 2018) that were examined in either inpatient or out-patient departments and had an established diagnosis of HF regardless of type, severity, treatment or date of onset ( $n=285745$ in 2018). We sought to compare the real practice data with the current standard of care. Currently available HF treatment guidelines state that ACEIs are recommended in all symptomatic patients since they reduce mortality and morbidity in patients with HFrEF. ACEIs are also recommended in patients with asymptomatic LV systolic dysfunction to reduce the risk of HF development, HF hospitalization and death ${ }^{1,8}$. ARBs are recommended only as an alternative in patients intolerant of an $\mathrm{ACEI}^{9}$. Sacubitril/valsartan is recommended as a replacement for an ACEI to further reduce the risk of HF hospitalization and death in ambulatory patients with HFrEF who remain symptomatic despite optimal treat-

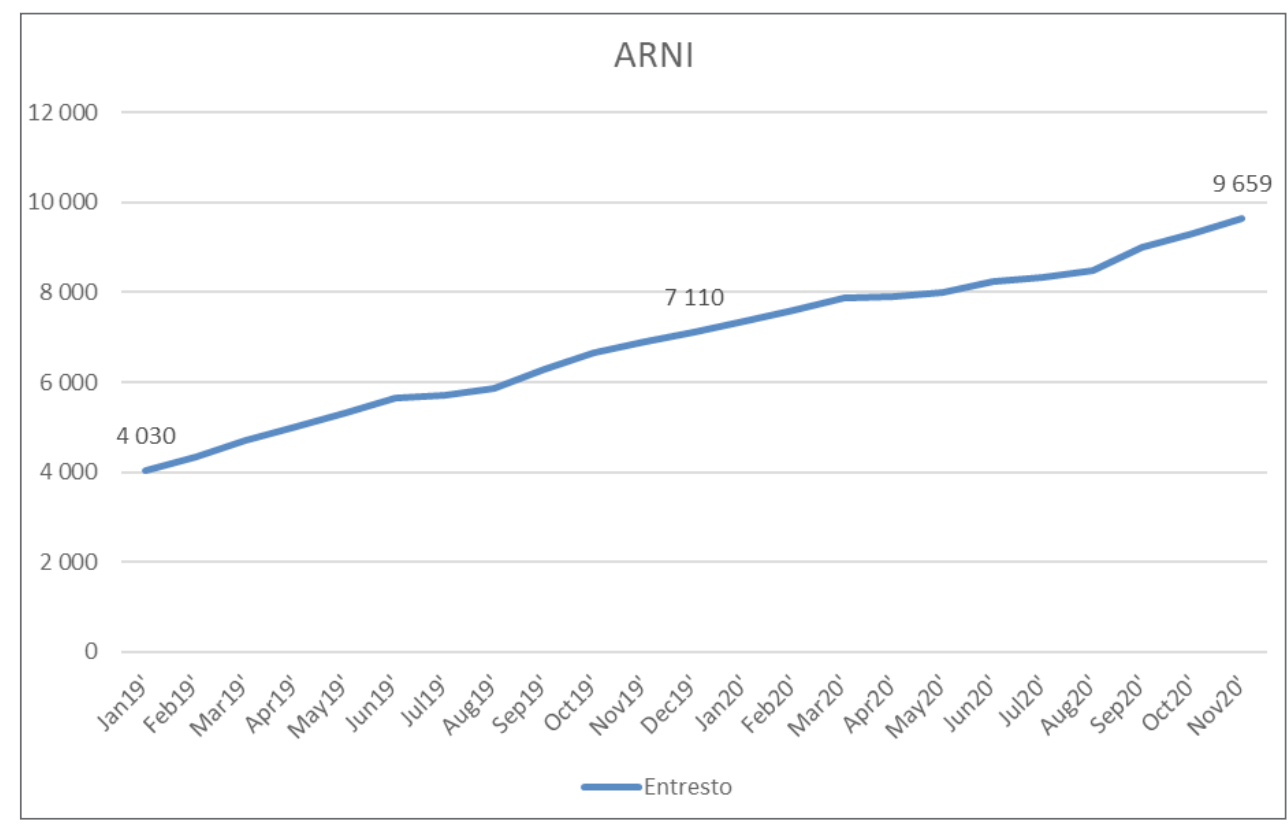

Fig. 1. ARNi utilization in 2019-2020. 


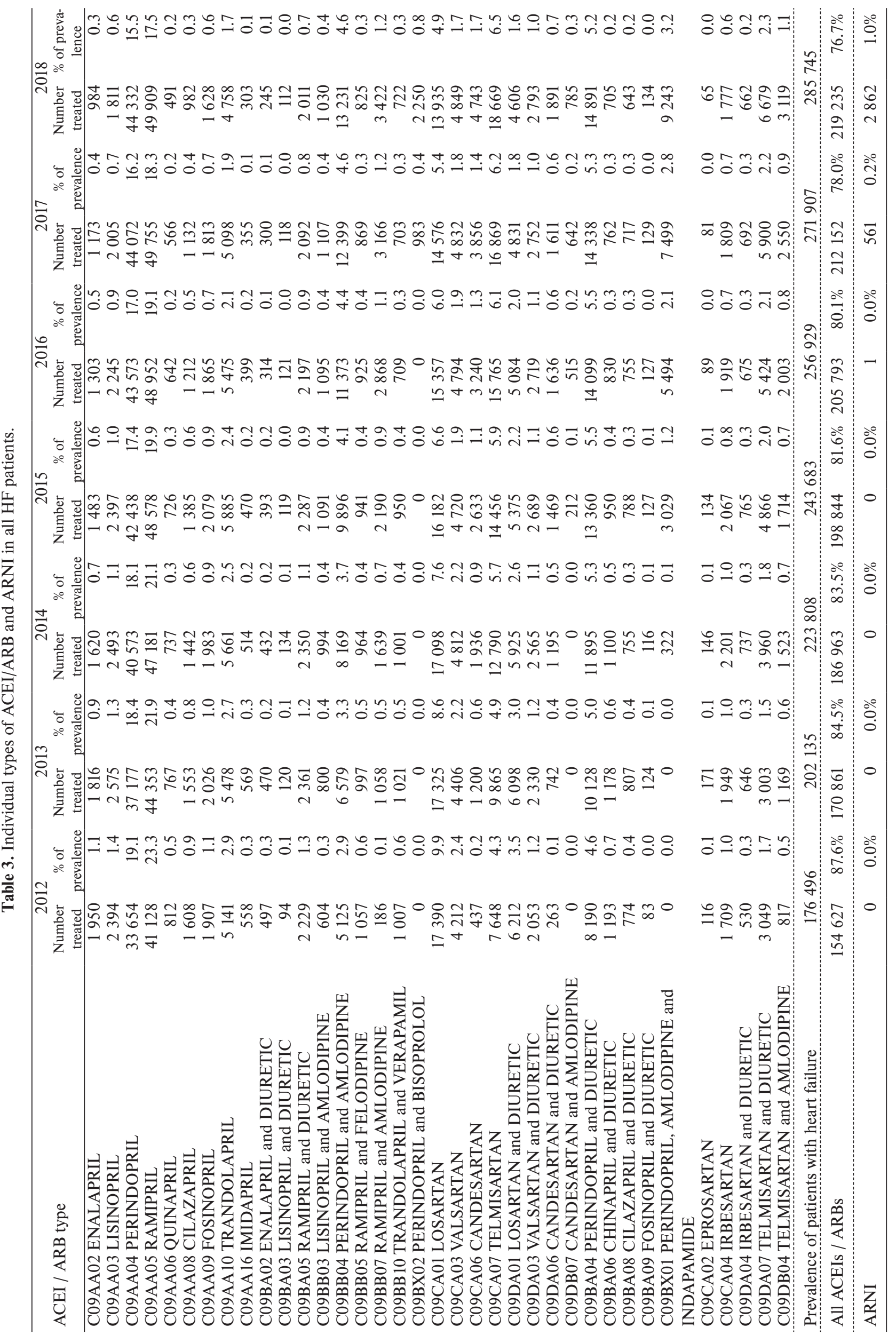


ment with an ACEI, a beta-blocker and mineralocorticoid receptor antagonist ${ }^{1}$.

Since we were analyzing data from all patients over the entire country, the case-mix is different than for the HF registries usually created in specialized centers ${ }^{10}$.

The prevalence of HF patients grew steadily in the last seven years that were evaluated. Even though the number of ACEI/ARB prescriptions has also significantly increased, the percentage of patients treated with these drugs decreased slightly. Since 2018, ARNIs began to be widely prescribed. Until 2018, their prescriptions were negligible. However, this increase was not large enough to explain the decrease in ACEI/ARB prescriptions. ARNIs became more widely prescribed in 2019 and 2020 and these years were not included in the core analysis. The reason for a decrease in $\mathrm{ACEI} / \mathrm{ARB}$ prescriptions is not obvious.

The majority of patients treated for HF in the Czech Republic in recent years were prescribed ramipril and perindopril. This has not changed in recent years. Despite an increase in the absolute number of prescriptions, the percentage of prescription in HF population decreased due to an increase in HF prevalence. Enalapril, lisinopril, quinapril, cilazapril, fosinopril and imidapril were each prescribed in $<1 \%$ of patients. In 2012 , the mostly prescribed ARB was losartan. This changed in the last years, when telmisartan became the most prescribed ARB. In one quarter of cases, ACEIs and ARBs were prescribed in a fixed combination with another drug.

These data can be compared to specific HF registries but the external validity of outcome of patients in these registries is limited because of the selectivity of individual hospitals and/or patients' participation. Patients in this analyzed population were added successively. This means that patients who were treated for HF in 2012 are still included in the analyzed population of HF patients in 2018 if they are still alive even if they are not treated for HF anymore.

An analysis of all types of ACEIs, ARBs and their combinations with other drugs, the percentage of ACEIs and ARBs use was slightly lower when compared to the HF registries ( $76.7 \%$ in 2018 vs $88.3 \%$ in the FAR-NHL registry) ( ref. $^{3}$ ). This is also similar in comparison with the ESC HF registry data, where in patients with $\mathrm{HFrEF}$, ACEI/ARBs were used in $91.7 \%$ of patients. A similar number of prescriptions were found in HFmrEF patients, whereas lower rates were noted in patients with $\mathrm{HFpEF}$ (ref. $\left.{ }^{11}\right)$.

The lower number of ACEI/ARBs usage in our registry may be attributable to the fact that a one-time diagnosis of HF was sufficient for the patient to be included in this HF group despite the fact that he or she is not treated anymore. If a medical procedure and/or examination at an in-patient or out-patient department using an I50.x ICD diagnosis code was accounted for in the given year (and not just anytime during 2010-2018), ACEi and ARBs were generally used in $88.6 \%$ in 2018 . This analysis is more comparable to the HF registries that include pa- tients with an episode of HF in the given year or at least examined or treated for the HF in the given year.

Using such an approach in pharmacotherapy analysis, we found a comparable number of ACEIs/ARBs with specific HF registries. This, with a recently increasing rate of ARNI prescriptions, shows a good implementation of the current standard of care in the Czech Republic. The large number of patients in our database diminishes the chance of selection bias. On the other hand, it inevitably leads to a loss of detail of individual patients' data. Due to the nature of the registry data, we are unable to specify the etiology of HF in the patients ${ }^{12}$. Data from echocardiography, including left ventricle ejection fraction (LVEF), ECG and laboratory samples are missing entirely. We thus cannot specify the severity of HF based on LVEF in our patients. Also, the data from coronary angiography are not available within the patient database. We could extrapolate data from other databases but they do not contain all HF patients in the whole country and thus could be linked with a serious bias. The majority of patients in our analysis (77.9\% of HF patients in 2018) had CAD and only $10 \%$ of patients had a cardiomyopathy in their diagnoses. This does not mean that patients with CAD had a disease significant enough to explain the development of HF (ref. ${ }^{13,14}$ ). These numbers are different from the HF registries (e.g., $42.9 \%$ of HF patients with CAD and $29.5 \%$ with idiopathic dilated cardiomyopathy in the ESC-HF Long-Term Registry; $50.1 \%$ of HF patients with CAD and $41.6 \%$ with idiopathic dilated cardiomyopathy in the Czech FAR-NHL Registry) (ref. ${ }^{10,15}$ ). A possible explanation could be under-reporting of a cardiomyopathy diagnosis in our database and thus the data about HF etiology should be taken with caution. In our registry, more than $60 \%$ of HF patients had a history of arrhythmias, mostly AF (49.7\% of HF patients in 2018). AF was thus also far more prevalent when compared to the ESC-HF Long-Term Registry (21.5\% of HF patients) and FARNHL registry (34.8\% of HF patients) (ref. ${ }^{10,15}$ ). However, the fact that almost a half of the patients had a history of AF does not mean that they were in AF all the time. In fact, only one AF paroxysm in the patients' history was enough for the diagnosis. The number of patients with a neoplasm may seem too high but the numbers reflect patients with a history of malignancy (and we report up to 40 years of history of malignancies in this cohort) and not patients suffering from a malignancy at the present time. The distribution of different types of neoplasms is similar to the most prevalent malignancies in the Czech Republic.

\section{Study limitations}

This is a general analysis of a real common practice and since some important data (LVEF, type of cardiomyopathy and the burden of AF) are missing, any comparisons with registries (that have however only a limited number of selected patients) should be taken with caution. Nevertheless, the fact that pharmacotherapy was analyzed in all patients in the country outweighs this limitation.

A large number of patients in our database diminish the chance of selection bias. On the other hand, it inevi- 
tably leads to little detail of individual patients' data. Data from echocardiography, ECG and laboratory samples are missing entirely.

We cannot rule out a population bias since all patients were diagnosed and treated in one developed country with highly advanced healthcare.

Individual patient records may be incorrect. These potential imperfections should not have an impact on the pharmacology analysis.

There is no single classification system for the causes of HF, with a significant overlap between potential categories. This makes a precise assessment of a single diagnosis of $\mathrm{HF}$ in such a database challenging.

\section{CONCLUSION}

In an analysis of ACEIs, ARBs and ARNIs utilization in all patients treated for heart failure in the given year in the whole country, we found a comparable rate of drug prescription in comparison with specific heart failure registries. This indicates a good translation of current standard of care into common clinical practice. Ramipril and perindopril remained the mostly prescribed ACEIs and telmisartan became the mostly prescribed ARB. Since 2018, ARNIs began to be widely prescribed.

Acknowledgements: This study has been implemented to the Czech Republic national action plan of cardiovascular prevention. The project aims for the early and systematic detection of patients with $\mathrm{CV}$ risks connected with the effective treatment intervention. The long-term goal of the project is the $5 \%$ reduction of $\mathrm{CV}$ mortality during the next 10 years.

This work was supported by the Czech Society of Cardiology via the Czech Republic National action plan of cardiovascular prevention.

Author contributions: RA, MT, TS: literature search, manuscript writing, data analysis, final approval; ML, LP, JD, JP, AS, VG, VC, MV: data analysis, final approval. Conflicts of interest statement: None declared.

\section{REFERENCES}

1. Ponikowski P, Voors AA, Anker SD, Bueno H, Cleland JGF, Coats AJS Falk V, González-Juanatey JR, Harjola VP, Jankowska EA, Jessup M, Linde C, Nihoyannopoulos P, Parissis JT, Pieske B, Riley JP, Rosano GMC, Ruilope LM, Ruschitzka F, Rutten FH, van der Meer P; ESC
Scientific Document Group. 2016 ESC Guidelines for the diagnosis and treatment of acute and chronic heart failure: The Task Force for the diagnosis and treatment of acute and chronic heart failure of the European Society of Cardiology (ESC)Developed with the special contribution of the Heart Failure Association (HFA) of the ESC. Eur Heart J 2016;37(27):2129-2200.

2. McMurray JJ, Packer M, Desai AS, Gong J, Lefkowitz MP, Rizkala AR, Rouleau JL, Shi VC, Solomon SD, Swedberg K, Zile MR; PARADIGM$\mathrm{HF}$ Investigators and Committees. Angiotensin-neprilysin inhibition versus enalapril in heart failure. N Engl J Med 2014;371(11):993-1004.

3. Spinar J, Spinarova L, Malek F, Ludka O, Krejci J, Ostadal P, Vondrakova D, Labr K, Spinarova M, Pavkova Goldbergova M, Benesova K, Jarkovsky J, Parenica J. Prognostic value of NT-proBNP added to clinical parameters to predict two-year prognosis of chronic heart failure patients with mid-range and reduced ejection fraction - A report from FAR NHL prospective registry. PLoS One 2019;14(3):e0214363.

4. Spinar J, Jarkovsky J, Spinarova L, Mebazaa A, Gayat E, Vitovec J, Linhart A, Widimsky P, Miklik R, Zeman K, Belohlavek J, Malek F, Felsoci M, Kettner J, Ostadal P, Cihalik C, Vaclavik J, Taborsky M, Dusek L, Littnerova S, Parenica J. AHEAD score--Long-term risk classification in acute heart failure. Int J Cardiol 2016:202:21-6.

5. Lund LH, Carrero JJ, Farahmand B, Henriksson KM, Jonsson Å, Jernberg T, Dahlström U. Association between enrolment in a heart failure quality registry and subsequent mortality-a nationwide cohort study. Eur J Heart Fail 2017;19(9):1107-116.

6. Omersa D, Farkas J, Erzen I, Lainscak M. National trends in heart failure hospitalization rates in Slovenia 2004-2012. Eur J Heart Fail 2016;18(11):1321-28

7. Spinar J, Hradec J, Spinarova L, Vitovec J. Souhrn Doporučených postupů ESC pro diagnostiku a léčbu akutního a chronického srdečního selhání z roku 2016. Cor et Vasa 2016, 58.5: e530-e568. (In Czech)

8. Garg R, Yusuf S. Overview of randomized trials of angiotensin-converting enzyme inhibitors on mortality and morbidity in patients with heart failure. JAMA 1995;273:1450-56.

9. Granger CB, McMurray JJV, Yusuf S, Held P, Michelson EL, Olofsson B, Ostergren J, Pfeffer MA, Swedberg K. Effects of candesartan in patients with chronic heart failure and reduced left-ventricular systolic function intolerant to angiotensin-converting-enzyme inhibitors: the CHARM-Alternative trial. Lancet 2003;362:772-76.

10. Spinar J, Vitovec J, Spinarova L. Pharmacotherapy of chronic heart failure after the first decade of 21st century. Vnitrni lekarstvi 2011;57(11):959-65. (In Czech)

11. Chioncel O, Lainscak M, Seferovic PM, Anker SD, Crespo-Leiro MG, Harjola VP, Parissis J, Laroche C, Piepoli MF, Fonseca C, Mebazaa A, Lund L, Ambrosio GA, Coats AJ, Ferrari R, Ruschitzka F, Maggioni AP, Filippatos G. Epidemiology and one-year outcomes in patients with chronic heart failure and preserved, mid-range and reduced ejection fraction: an analysis of the ESC Heart Failure Long-Term Registry. Eur J Heart Fail 2017;19(12):1574-85.

12. Spinar J, Vitovec J, Spinarova L. Heart Failure with Preserved Ejection Fraction. Vnitřní lékařství 2016;62(7-8):646-51. (In Czech)

13. Spinarova L, Spinar J, Vitovec J. Pharmacotherapy following myocardial infarction. Vnitřní lékařství 2011;57(11):966-70. (In Czech)

14. Spinar J, Vitovec J, Spinarova L. FARIM-FARmakoterapie po Infarktu Myokardu (Post-Myocardial Infarction Pharmacotherapy Study). Vnitrni lekarstvi 2011;57(9):778-84.

15. Vitovec J, Spinarova L, Spinar J. Sekundární prevence po infarktu myokardu-režimové a farmakologické postupy. Interní medicína pro praxi 2011;13(5):202-4. (In Czech) 